Cite this: Dalton Trans., 2014, 43, 6925

Received 31st January 2014, Accepted 4th March 2014

DOI: $10.1039 / c 4 d t 00338 a$ www.rsc.org/dalton

\title{
Revised crystal structure and luminescent properties of gadolinium oxyfluoride $\mathrm{Gd}_{4} \mathrm{O}_{3} \mathrm{~F}_{6}$ doped with $\mathrm{Eu}^{3+}$ ions $\uparrow$
}

\author{
Tomasz Grzyb, ${ }^{\star a}$ Rafal J. Wiglusz, ${ }^{\star b}$ Vitali Nagirnyi, ${ }^{c}$ Aleksei Kotlov ${ }^{d}$ and Stefan Lis ${ }^{a}$ \\ The structure of gadolinium oxyfluoride nanoparticles was revised. Extensive studies including X-ray diffr- \\ action and Rietveld refinement as well as Fourier transform infrared spectroscopy and Raman spec- \\ troscopy confirmed the monoclinic $P 12 / \mathrm{c} 1$ crystal structure of $\mathrm{Gd}_{4} \mathrm{O}_{3} \mathrm{~F}_{6}$. Morphological analysis using \\ transmission electron microscopy showed the nanocrystallinity of the materials prepared via the sol-gel \\ Pechini's method. The luminescent properties of the prepared materials with different concentrations of \\ $\mathrm{Eu}^{3+}$ ions were characterized by emission spectroscopy. The phosphors obtained were investigated in the \\ vacuum ultraviolet range using synchrotron radiation. The Judd-Ofelt parameters $\left(\Omega_{2}, \Omega_{4}\right)$ and emission \\ efficiencies $\eta$ were calculated and are discussed in detail.
}

\section{Introduction}

The research in the area of rare earth oxyfluorides (REOF) is thriving not only through the rich structural varieties observed in the materials but also through their widely varying luminescence properties that promise potential applications. ${ }^{1-15}$ The structural properties of REOF were mostly investigated by Zachariasen in the $1950 \mathrm{~s} .{ }^{16}$ It has been determined that as a result of solid state reaction between rare earth fluorides and their oxides at high temperatures, oxyfluorides are formed. They crystallize in two different phases, tetragonal and rhombohedral. Unlike rhombohedral oxyfluorides, the ones with the tetragonal crystal structure suffer from instability and form usually nonstoichiometric compounds. Their general formula is $\mathrm{REO}_{n} \mathrm{~F}_{3-2 n}, 0.7<n<1 .{ }^{16} \mathrm{~A}$ high similarity between $\mathrm{F}^{-}$and $\mathrm{O}^{2-}$ ionic radii is mainly responsible for the variations in the tetragonal phase. These ions can substitute for each other in the crystal structure. The crystallographic structure of YOF and LaOF can be obtained as a result of a tetragonal or rhombohedral deformation of the regular cubic elementary crystal cell of $\mathrm{CaF}_{2}$. Further research has brought about a

\footnotetext{
${ }^{a}$ Department of Rare Earth, Faculty of Chemistry, Adam Mickiewicz University, Umultowska 89b, 61-614 Poznan, Poland. E-mail: tgrzyb@amu.edu.pl ${ }^{b}$ Institute of Low Temperature and Structure Research, Polish Academy of Sciences, P.O.Box 1410, 50-950 Wroclaw, Poland.E-mail: R.Wiglusz@int.pan.wroc.pl 'Institute of Physics, University of Tartu, Riia 142, 51014 Tartu, Estonia ${ }^{d}$ Photon Science Division at DESY, Gebaude 25b/309 Notkestr. 85, D-22607 Hamburg, Germany

$\dagger$ Electronic supplementary information (ESI) available. See DOI: 10.1039/ c4dt00338a
}

better understanding of other lanthanide oxyfluoride systems, giving detailed information about their crystallography. ${ }^{17-19}$

Besides tetragonal and rhombohedral forms also a cubic form has been obtained as a result of the phase transition from their rhombohedral form at high temperatures. ${ }^{20,21}$ The main crystallographic space groups assigned to REOF are: tetragonal $P_{4} / n m m$ and rhombohedral $R \overline{3} \mathrm{~m}$. In the tetragonal structure, $\mathrm{RE}^{3+}$ ions occupy sites with $C_{4 \mathrm{v}}$ symmetry, whereas in the rhombohedral structure, the local symmetry of $\mathrm{RE}^{3+}$ is $C_{3 \mathrm{v}}{ }^{2}{ }^{2}$

The more accurate analysis of nonstoichiometric oxyfluorides has shown higher than expected complexity of these materials. ${ }^{22-24}$ The oxyfluorides of the composition $\operatorname{RE}(\mathrm{O}, \mathrm{F})_{2+\delta}$, where $0.4 \geq \delta \geq 0$, crystallize in a tetragonal form; however, for $\mathrm{RE}_{n} \mathrm{O}_{n-1} \mathrm{~F}_{n+2}$, where $5 \leq n \leq 9, \mathrm{RE}=\mathrm{Y}, \mathrm{Sm}-\mathrm{Lu}$, the orthorhombic crystal structure is more stable and probable.

The crystallographic data for gadolinium oxyfluoride are incomplete and this compound requires additional studies. Up to now, the tetragonal structure has been assigned to $\mathrm{Gd}_{4} \mathrm{O}_{3} \mathrm{~F}_{6}$ only in one scientific article; however, there no data have been given about its crystallographic space group. ${ }^{25}$ As this compound, similar to other rare earth oxyfluorides, could be used as a host for luminescent $\mathrm{Ln}^{3+}$ ions (where $\mathrm{Ln}^{3+}=$ $\mathrm{Eu}^{3+}, \mathrm{Yb}^{3+} / \mathrm{Er}^{3+}$, etc. $){ }^{9,11,13,15}$ there is a need to know its structure and determine the crystallographic properties.

Tetragonal oxyfluorides of the formula $\mathrm{REO}_{n} \mathrm{~F}_{3-2 n}, 0.7<n<$ 1 , contain fluorine $\mathrm{F}^{-}$ions in the interstitial sites in a crystal structure derived from that of fluorite $\mathrm{CaF}_{2} \cdot{ }^{16}$ Takashima et al. proposed a different crystal structure for the binary rare earth oxyfluorides, $\mathrm{RE}_{2}{ }^{\mathrm{I}} \mathrm{RE}_{2}{ }^{\mathrm{II}} \mathrm{O}_{3} \mathrm{~F}_{6}$, where $\mathrm{RE}^{\mathrm{I}}=\mathrm{La}, \mathrm{Nd}, \mathrm{RE}^{\mathrm{II}}=\mathrm{Y}, \mathrm{Eu}$, Gd. In the presented studies, concerning mainly the ionic conductivity of oxyfluorides, a monoclinic crystal system of the 
$P 2 / C$ space group is reported. ${ }^{26-31}$ The assignment of a tetragonal structure to binary rare earth oxyfluorides results in a discrepancy in the positions of XRD reflections with the reference pattern. Also the shape of XRD peaks recorded, their intensity and the ratio between them are in disagreement with the theoretical pattern. Additionally, the presence of a weak peak at $33.84^{\circ} 2 \theta$ could not be attributed to any of crystallographic planes. A monoclinic structure could be considered as a slightly distorted tetragonal lattice derived from the fluorite structure. The refinement with the structural parameters of a monoclinic crystal system allowed us to solve the structure of the $\mathrm{Gd}_{4} \mathrm{O}_{3} \mathrm{~F}_{6}$ material. The $P 2 / c$ monoclinic crystal system was assigned as the most probable for this compound. The presented results show that the positions of ions in the $\mathrm{Gd}_{4} \mathrm{O}_{3} \mathrm{~F}_{6}$ crystallographic lattice are very similar to those in the tetragonal structure. Hence, the $\mathrm{Gd}_{4} \mathrm{O}_{3} \mathrm{~F}_{6}$ structure can be treated as pseudo-tetragonal.

Luminescence properties of lanthanide ions $\left(\mathrm{Ln}^{3+}\right)$ are well known and widely studied because of their narrow line-width emission bands, large Stokes shifts, high quantum yields, long lifetimes and photostability. ${ }^{32-37}$ The presence of (Gd,Eu)-F and $(\mathrm{Gd}, \mathrm{Eu})-\mathrm{O}$ bonds in the $\mathrm{Eu}^{3+}$-doped oxyfluorides can increase absorption in the vacuum ultraviolet (VUV) range. This property is useful for new, $\mathrm{Hg}$-free sources of fluorescent light. $^{38,39}$ Quantum cutting phenomena which are prone to occur in VUV absorbing phosphors is another advantage of these materials, enabling the emission quantum yield higher than $100 \% .^{40,41}$ Also white LEDs (light emitting diodes) may be an area where luminescence of $\mathrm{Ln}^{3+}$ ions is important. ${ }^{42-44}$

The sol-gel method used for the synthesis of $\mathrm{Gd}_{4} \mathrm{O}_{3} \mathrm{~F}_{6}$ and relatively low temperature of calcination of the precursors prepared in this way could be used for the production of phosphors.

\section{Experimental}

\section{Synthesis}

Gadolinium oxyfluorides, $\mathrm{Gd}_{4} \mathrm{O}_{3} \mathrm{~F}_{6}$ and $\mathrm{Gd}_{4} \mathrm{O}_{3} \mathrm{~F}_{6}: \mathrm{Eu}^{3+}$, were synthesized by the modified Pechini's method. ${ }^{45}$ The starting materials were gadolinium and europium oxides, $\mathrm{Gd}_{2} \mathrm{O}_{3}$ and $\mathrm{Eu}_{2} \mathrm{O}_{3}$ (Stanford Materials 99.99\%, United States), nitric acid $\mathrm{HNO}_{3}$ (POCh S.A., ultra-pure, Poland), ammonium fluoride $\mathrm{NH}_{4} \mathrm{~F}$ (POCh S.A., ACS grade 98+\%, Poland), citric acid monohydrate (CHEMPUR, p.a. grade, Poland), and ethylene glycol (CHEMPUR, p.a. grade, Poland).

To synthesize pure matrix without dopant ions, $\mathrm{Gd}_{4} \mathrm{O}_{3} \mathrm{~F}_{6}$, the gadolinium oxide (0.9166 g) was dissolved in $\mathrm{HNO}_{3}$ and evaporated several times in order to remove excess amount of $\mathrm{HNO}_{3}$. The beaker containing the obtained $\mathrm{Gd}\left(\mathrm{NO}_{3}\right)_{3}$ was filled up to $100 \mathrm{ml}$ with distilled water and $24 \mathrm{~g}$ of citric acid and then $4 \mathrm{ml}$ of ethylene glycol were added. A large excess of citric acid was used to prevent the precipitation of lanthanide fluorides ( $24 \mathrm{~g}$ of citric acid and $4 \mathrm{ml}$ of ethylene glycol per $1 \mathrm{~g}$ of product). Upon intensive stirring, an aqueous solution of $0.35 \mathrm{~g}$ ammonium fluoride in $10 \mathrm{ml}$ of water was slowly dropped into the solution (with $25 \%$ excess because of the stoichiometric amounts of $\mathrm{Gd}^{3+}$ ions). The solution was heated at $80{ }^{\circ} \mathrm{C}$ for 24 hours in order to evaporate the water and to obtain a gel. The prepared precursor was annealed at 500-900 ${ }^{\circ} \mathrm{C}$ under the air atmosphere for $2 \mathrm{~h}$. A similar procedure was used for the synthesis of $\mathrm{Eu}^{3+}$-doped samples, based on the stoichiometric calculations which assumed replacement of $\mathrm{Gd}^{3+}$ by $\mathrm{Eu}^{3+}$ ions in the structure of $\mathrm{Gd}_{4} \mathrm{O}_{3} \mathrm{~F}_{6}$.

\section{Characterization}

Thermogravimetric analysis (TG) and differential thermal gravimetry (DTG) were performed using a Haas DSC XP-10i calorimeter. The X-ray diffraction (XRD) patterns were collected in the $2 \theta$ range $10-80^{\circ}$ with an X'Pert PRO X-ray diffractometer (Cu, $K \alpha_{1}: 1.54060 \AA$ ) (PANalytical). The IR absorption spectrum was recorded between 400 and $4000 \mathrm{~cm}^{-1}$ on a Fourier transform infrared (FT-IR) spectrophotometer Bruker FT-IR IFS $66 / \mathrm{s}$. The material was mixed with $\mathrm{KBr}$ and then pressed to discs. Raman spectra were taken using a LabRam HR 800 Horiba Yvon Jobin system equipped with a $9 \mathrm{~mW}$ HeNe laser emitting a $632.8 \mathrm{~nm}$ line. The $\mathrm{Gd}_{4} \mathrm{O}_{3} \mathrm{~F}_{6}$ powders were investigated by transmission electron microscopy (TEM) using a Philips CM-20 SuperTwin microscope operating at $200 \mathrm{kV}$. Specimens for TEM were prepared by dispersing a small amount of the sample in methanol and putting a droplet of the suspension on a copper microscope grid covered with perforated carbon. Diffractograms were used in crystallographic data refinement with the help of the Rietveld method. ${ }^{46}$ The Maud 2.33 software was used to perform the Rietveld refinement of cell parameters and the phase composition. ${ }^{47}$ The quality of structural refinement was generally checked by $R$-values $\left(R_{\mathrm{w}}\right.$, $\left.R_{\mathrm{wnb}}, R_{\mathrm{all}}, R_{\mathrm{nb}}\right)$, and these numbers are easy to detect as they are consistent with a monoclinic structure. However, other parameters with additional functions were applied to find a structural refinement with better quality and reliability.

The luminescence characteristics of the synthesized samples were studied with a Hitachi F-7000 fluorescence spectrophotometer at room and liquid nitrogen temperatures (300 and $77 \mathrm{~K}$ ) with a $150 \mathrm{~W}$ xenon lamp as an excitation source. Excitation and emission spectra were corrected for the instrumental response. The luminescence decay curves of the prepared samples were measured on a Photon Technology Int. QuantaMasterTM 40 spectrophotometer equipped with an Opotek Inc. Opolette 355LD UVDM tunable laser with a repetition rate of $20 \mathrm{~Hz}$ as an excitation source and a Hamamatsu R928 photomultiplier as a detector. The curve fit for the decay data was performed with the Origin 9.0 software. The fit with the time traces was at least $R^{2}=0.998$ and the errors were not larger than $\tau_{\text {err }}<0.01 \mathrm{~ms}$.

The synchrotron radiation study of powder samples was performed at the SUPERLUMI station of HASYLAB, Hamburg, Germany. The setup has been described in detail elsewhere. ${ }^{48}$ Luminescence spectra with resolution $1 \mathrm{~nm}$ were recorded with a SpectraPro308i (Acton) spectrograph equipped with a CCD camera. The second arm of the spectrograph equipped with a Hamamatsu photomultiplier R6358P was used for 
measuring the excitation spectra of different emission lines. In the latter case, the slits of the spectrograph were set to a spectral interval of $10 \mathrm{~nm}$. The excitation spectra were corrected for the spectral distribution of the incident light.

\section{Results and discussion}

\section{Structure and morphology}

Gadolinium oxyfluoride, $\mathrm{Gd}_{4} \mathrm{O}_{3} \mathrm{~F}_{6}$, is a relatively less studied material as can be concluded, for example, from the lack of accurate crystallographic data for this compound. It has attracted undeservedly little attention of researchers and only one example of its use as a matrix for up-converting $\mathrm{Yb}^{3+}$, $\mathrm{Tm}^{3+}$ and $\mathrm{Er}^{3+}$ ions could be found. ${ }^{11}$ This material could be a good potential host for luminescent lanthanide ions like $\mathrm{Eu}^{3+}$ and $\mathrm{Tb}^{3+}$. Relatively low phonon energies of $\mathrm{Gd}_{4} \mathrm{O}_{3} \mathrm{~F}_{6}$ cause lower efficiency of the phonon relaxation from the ${ }^{5} \mathrm{D}_{1}$ excited state of $\mathrm{Eu}^{3+}$ ions to the ${ }^{5} \mathrm{D}_{0}$ state. A large energy gap $\left(\sim 12000 \mathrm{~cm}^{-1}\right)$ between the first excited state, ${ }^{5} \mathrm{D}_{0}$, and the highest ground state of $\mathrm{Eu}^{3+}$ ions, ${ }^{7} \mathrm{~F}_{J}$, makes phonon relaxation between them very improbable. ${ }^{49}$

The synthesized $\mathrm{Gd}_{4} \mathrm{O}_{3} \mathrm{~F}_{6}$ sample was analysed precisely by the Rietveld refinement in the isotropic approach in order to obtain the structural information about this compound.

Table 1 shows the experimental and calculated results of the Rietveld analysis of gadolinium oxyfluoride. These results confirmed that the synthesized compound was monophasic. The crystal structure of $\mathrm{Gd}_{4} \mathrm{O}_{3} \mathrm{~F}_{6}$ was determined to be monoclinic with the space group $P 12 / c 1$.

The Rietveld analysis could be applied to any of the compounds prepared within the compositional domain and occurring in a stable, single phase. However, our aim was to find a structural model suitable for all the chemical compositions within the stable structural domain with pure phases.

The structure of the new $\mathrm{Gd}_{4} \mathrm{O}_{3} \mathrm{~F}_{6}$ compound was refined from powder XRD data in a tetralanthanide trioxyfluoride structure model. ${ }^{29}$ The instrumental parameters used to describe the Rietveld profile were as follows: zero-point in $2 \theta$, background parameters, three peak-shape parameters, $U, V$ and $W$, in the formula $H^{2}=U \tan ^{2} \theta+V \tan \theta+W$ to describe a pseudo-Voigt peak with full width at half maximum, $H$, which increases with $\theta_{i}$. The structure parameters used were: a scale factor, the lattice constant, the positional coordinate and the occupancy factors (Table 1) of all atoms and the isotropic temperature factors.

Fig. 1 shows typical observed, calculated, and difference profiles for the synthesized $\mathrm{Gd}_{4} \mathrm{O}_{3} \mathrm{~F}_{6}$. In all cases, the agreement between the observed and calculated Rietveld profiles is excellent and the final $R$ factors are satisfactory. This model fits the observed intensity provided that the structural parameters from Table 1 are taken.

In this structure, the cation sites, Gd1 and Gd2, are coordinated by oxygen and fluorine ions with $\mathrm{CN}=9$, while the occupancy of the $2 \mathrm{f}$ site by $\mathrm{F}^{-}$and $\mathrm{O}^{2-}$ is 0.4 and 0.5 , respectively (Fig. 2). In the $\mathrm{Gd}_{4} \mathrm{O}_{3} \mathrm{~F}_{6}$ structure, the ionic arrangement
Table 1 Atomic and crystal cell parameters for monoclinic $\mathrm{Gd}_{4} \mathrm{O}_{3} \mathrm{~F}_{6}$ : cell dimensions ( $a, b$ and $c)$, angles $(\beta)$ and volume $(V$; atom site coordinates $(x, y$ and $z)$, isotropic atomic displacement parameter $\left(B_{\text {iso }}\right)$ and the goodness of fits between experimental and theoretical diffraction pattern values $\left(R_{\mathrm{w}}, R_{\mathrm{wnb}}, R_{\mathrm{all}}\right.$ and $\left.R_{\mathrm{nb}}\right)$

\begin{tabular}{ll} 
Sample & $\mathrm{Gd}_{4} \mathrm{O}_{3} \mathrm{~F}_{6}$ \\
Space group & $\mathrm{Monoclinic} P 12 / c 1(13)$ \\
Formula units per cell & $Z=1$ \\
Calculated cell parameters & $a=3.9498(8) \AA$ \\
& $b=11.2280(6) \AA$ \\
& $c=5.5420(9) \AA$ \\
& $\beta=134.56(3)^{\circ}$ \\
& $V=175.12(517) \AA^{3}$ \\
$R_{\mathrm{w}}$ & $3.29 \%$ \\
$R_{\mathrm{wnb}}$ & $2.06 \%$ \\
$R_{\mathrm{all}}$ & $2.26 \%$ \\
$R_{\mathrm{nb}}$ & $2.72 \%$ \\
\hline
\end{tabular}

Selected contacts

\begin{tabular}{ll}
\hline Gd-Gd & $3.9498(8) \AA$ \\
Gd-O & $2.1445(1) \AA$ \\
Gd-O/F & $2.1469(4) \AA$ \\
Gd-F & $2.2718(3) \AA$ \\
Gd-O-Gd & $133.813(10)^{\circ}$ \\
Gd-F-Gd & $120.760(9)^{\circ}$ \\
\hline
\end{tabular}

\begin{tabular}{llllll}
\hline Atom & Wyckoff positions & $x$ & $y$ & $z$ & $B_{\text {iso }}\left[\AA^{2}\right]$ \\
\hline Gd1 & 2e & 0 & $0.115(x)$ & 0.25 & $0.135(5)$ \\
Gd2 & 2e & 0 & $0.615(x)$ & 0.25 & $0.141(6)$ \\
O1 & 2f & 0.5 & $0.960(x)$ & 0.75 & $1.021(4)$ \\
O2 & 2e & 0 & $0.836(x)$ & 0.25 & $1.023(2)$ \\
O3 & 2e & 0 & $0.306(x)$ & 0.25 & $1.024(1)$ \\
F1 & 2f & 0.5 & $0.960(x)$ & 0.75 & $1.025(5)$ \\
F2 & 2f & 0.5 & $0.285(x)$ & 0.75 & $1.021(4)$ \\
F3 & 2f & 0.5 & $0.462(x)$ & 0.75 & $1.022(3)$ \\
F4 & 2f & 0.5 & $0.789(x)$ & 0.75 & $1.021(1)$
\end{tabular}

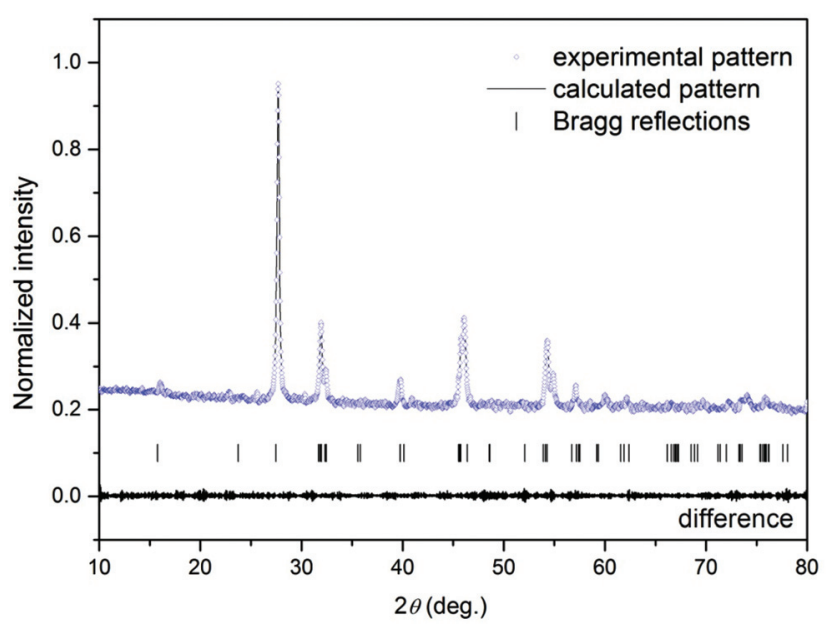

Fig. 1 The Rietveld profile fit of X-ray diffraction data of $\mathrm{Gd}_{4} \mathrm{O}_{3} \mathrm{~F}_{6}$ annealed at $500{ }^{\circ} \mathrm{C}$ for $2 \mathrm{~h}$.

was supposed to be highly ordered with two kinds of ion clusters, $\mathrm{GdO}_{0.5} \mathrm{~F} \cdot \mathrm{O}_{0.5}$ and $\mathrm{GdF}_{2} \cdot \mathrm{O}_{0.5}{ }^{29}$ The linkage of these clusters was estimated to be somewhat disordered. The disorder in the anion arrangement was caused by the disorder in the cation arrangement. Consequently, the occupancy of $2 \mathrm{e}$ sites 
a)
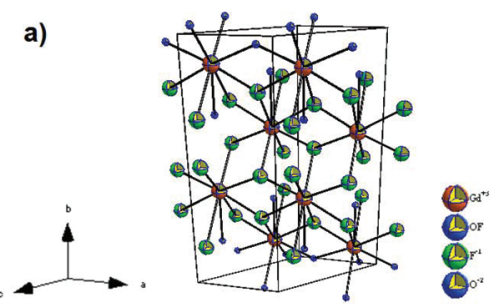

b)
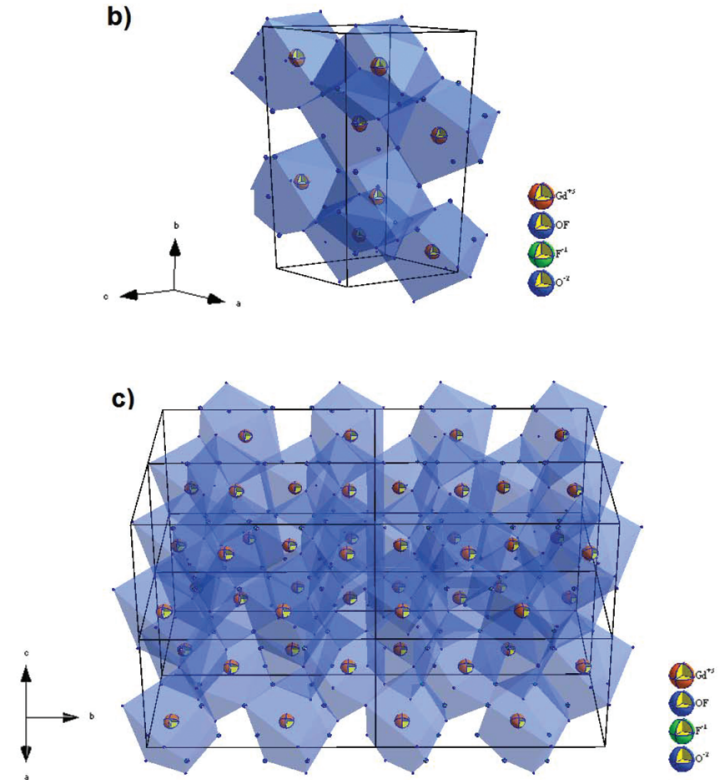

Fig. 2 The structure of the monoclinic $\mathrm{Gd}_{4} \mathrm{O}_{3} \mathrm{~F}_{6}$ phase with (a) unit cell and ( $b$ and $c$ ) the coordination environment of $\mathrm{Gd}^{3+}$ ions.

by oxygen ions remained at 0.5 , whereas $2 \mathrm{f}$ sites layered at the $y=0$ plane were occupied partially by fluoride ions. Because the occupancy of $2 \mathrm{f}$ sites by fluorine ions and oxygen ions is less than 1.0, then oxygen and fluorine ion conductivity could be considered in this material. ${ }^{28,50}$

The stoichiometric composition of rare earth oxyfluorides is strongly affected by the amount of fluorine ions in the sample. It is greatly important to maintain the required composition of the initial precursor for the synthesis of an appropriate material phase. The Pechini's method enables a full control of the $\mathrm{F}^{-}$amount because the initial concentration can be easily changed with the quantity of $\mathrm{NH}_{4} \mathrm{~F}$ in the gel. In this way it is possible to obtain a rhombohedral as well as a pseudo-tetragonal form of gadolinium oxyfluoride.

Thermo-gravimetric analysis of powders purified from the reaction mixture was performed in air in order to identify the processes occurring during the thermal treatment (see Fig. 3). The mass loss up to $550{ }^{\circ} \mathrm{C}$ was attributed to the decomposition of organic components. The $\mathrm{Gd}_{4} \mathrm{O}_{3} \mathrm{~F}_{6}$ product is formed above $550{ }^{\circ} \mathrm{C}$. The intense peak around $500{ }^{\circ} \mathrm{C}$ visible in the DTA curve is an effect of the exoenergetic decomposition of the organic resin and simultaneous crystallization of the $\mathrm{Gd}_{4} \mathrm{O}_{3} \mathrm{~F}_{6}$ product. Temperature increase has a very small effect on the sample above $600{ }^{\circ} \mathrm{C}$, considering the lack of any larger

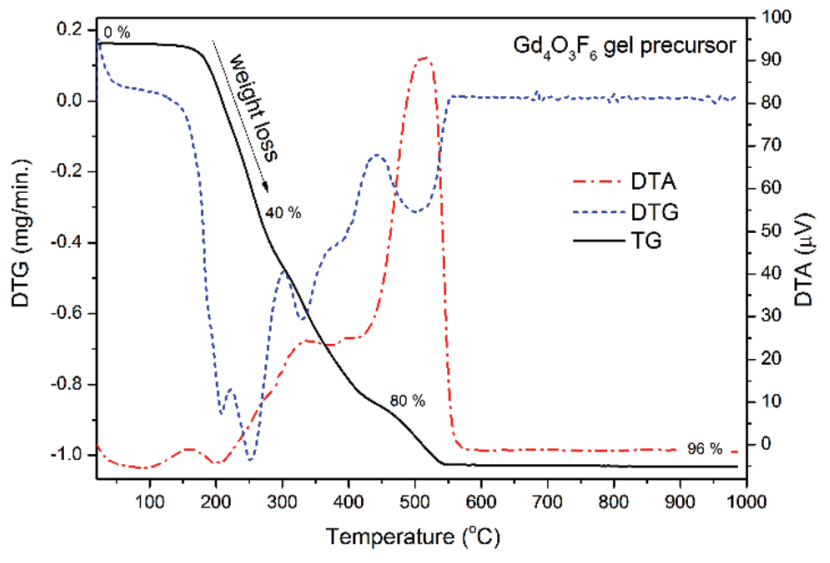

Fig. 3 DTG/TG analysis of the $\mathrm{Gd}_{4} \mathrm{O}_{3} \mathrm{~F}_{6}$ gel precursor.

peaks at these temperatures. Finally, only about $4 \%$ of the gel precursor is transferred into the powder product.

The phase composition of the samples prepared at temperatures from the range $500-900{ }^{\circ} \mathrm{C}$ was calculated with the help of Rietveld refinement. Above $500{ }^{\circ} \mathrm{C}$, a phase transition to the rhombohedral GdOF form was observed. At temperatures higher than $600{ }^{\circ} \mathrm{C}$ oxyfluorides decomposed into $\mathrm{Gd}_{2} \mathrm{O}_{3}$ oxide. From Fig. 3, the optimal temperature for annealing the precursor gel can be found. Heating the gel at $500{ }^{\circ} \mathrm{C}$ allows the formation of the product, and at the same time it is temperature sufficient for the decomposition of organic contaminants. The product obtained at $500{ }^{\circ} \mathrm{C}$ was used in further structural analysis including IR and Raman spectroscopy.

In order to investigate the morphology and structure of the final products, TEM and SAED characterization was carried out for the $\mathrm{Gd}_{4} \mathrm{O}_{3} \mathrm{~F}_{6}$ sample heat treated at $500{ }^{\circ} \mathrm{C}$ (Fig. 4).
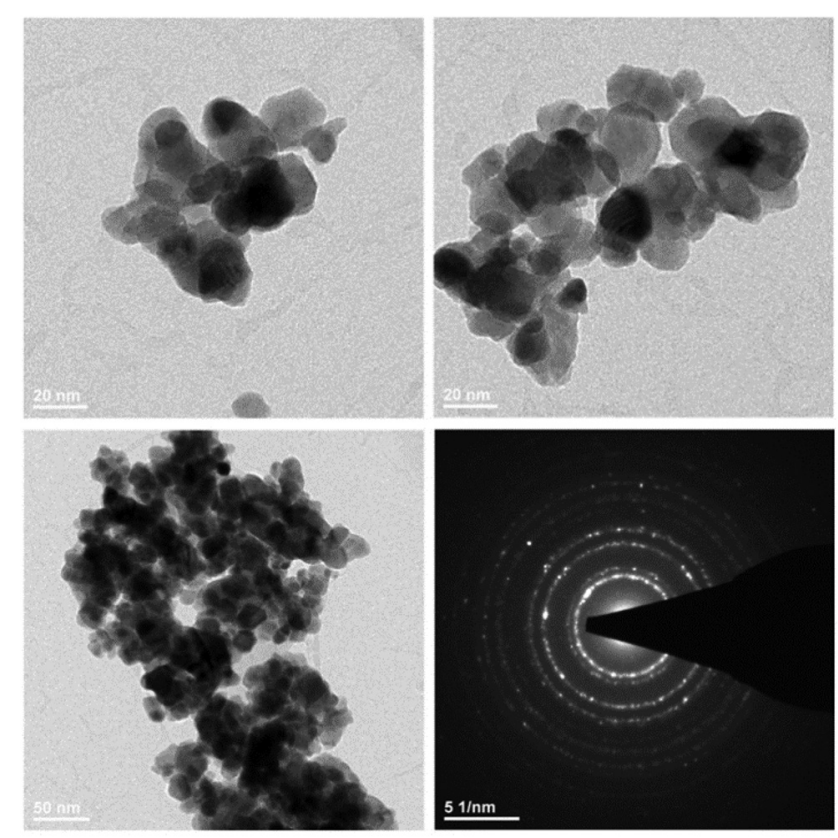

Fig. 4 TEM and SAED images of $\mathrm{Gd}_{4} \mathrm{O}_{3} \mathrm{~F}_{6}$ prepared at $500^{\circ} \mathrm{C}$. 
TEM images showed the nanocrystalline structure of powders, whereas the average nanocrystal size taken from TEM was $26 \pm$ $8 \mathrm{~nm}$. The synthesis conditions and character of the used solgel method result in formation of agglomerates. However, the agglomeration of individual crystallites is relatively weak and there are no sintered and melted forms visible in the TEM image. Selected area diffraction (SEAD) shows the polycrystalline properties of the powders prepared.

The number of expected IR and Raman peaks can be found from the described crystal structure of $\mathrm{Gd}_{4} \mathrm{O}_{3} \mathrm{~F}_{6}$. According to the factor group analysis, for the monoclinic $\mathrm{Gd}_{4} \mathrm{O}_{3} \mathrm{~F}_{6}, 6$ IR and 6 Raman peaks should be observed in the measured spectra. There are 16 atoms in the unit cell and therefore $3 N=$ 48 degrees of freedom which are divided into 12 modes (IR active modes are labelled as IR and Raman modes as R):

$$
\Gamma_{\text {opt }}=2 A_{\mathrm{g}}(\mathrm{R})+2 A_{\mathrm{u}}(\mathrm{IR})+4 B_{\mathrm{g}}(\mathrm{R})+4 B_{\mathrm{u}}(\mathrm{IR})
$$

The FT-IR spectrum of the $\mathrm{Gd}_{4} \mathrm{O}_{3} \mathrm{~F}_{6}$ sample is shown in Fig. 5. It demonstrates characteristic intense bands in the range of $3000-3750 \mathrm{~cm}^{-1}$ connected with the $\mathrm{O}-\mathrm{H}$ stretching vibrations. The peaks near $1530 \mathrm{~cm}^{-1}$ and $1380 \mathrm{~cm}^{-1}$ can be assigned to the $\mathrm{C}-\mathrm{O}$ absorption. These two bands could be connected with traces of organic impurities present in the sample or with absorption by $\mathrm{CO}_{2}$ and $\mathrm{H}_{2} \mathrm{O}$ adsorbed at the powder surface. The $\mathrm{C}-\mathrm{O}$ and $\mathrm{O}-\mathrm{H}$ groups with high energy vibrations may be present in the samples because the character of a sol-gel process involves the decomposition processes of organic compounds forming a gel. The absorption peak at $527 \mathrm{~cm}^{-1}$ is ascribed to the vibration of the $\mathrm{Gd}-\mathrm{O}$ bond. The $\mathrm{Gd}_{4} \mathrm{O}_{3} \mathrm{~F}_{6}$ compound shows also absorption in the range below $400 \mathrm{~cm}^{-1}$ (shown as inset in Fig. 5). The absorption in this range is observed as a broad peak with the minimum of transmittance at $367 \mathrm{~cm}^{-1}$. The broad shape of this absorption band can be attributed to the disordered arrangement of the ions in the crystal lattice of the $\mathrm{Gd}_{4} \mathrm{O}_{3} \mathrm{~F}_{6}$ compound. There is also similarity in absorption bands in this range between the monoclinic and tetragonal or cubic REOF. ${ }^{51}$

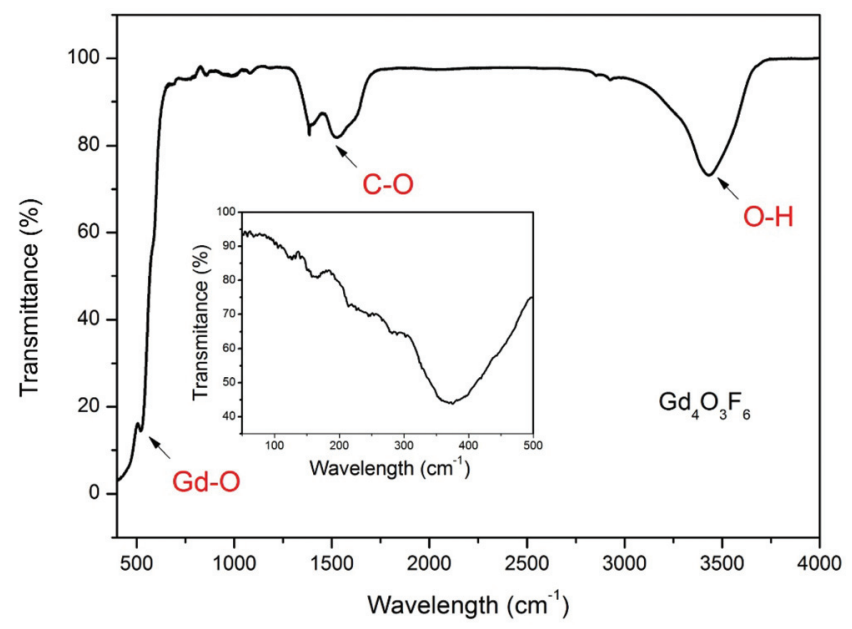

Fig. 5 IR spectra of $\mathrm{Gd}_{4} \mathrm{O}_{3} \mathrm{~F}_{6}$ nanomaterial.
The FT-IR spectra of the rhombohedral REOF are much more complex, demonstrating at least two absorption bands in this region. ${ }^{52}$ In the IR spectrum shown in the inset, the structure of absorption bands is complex due to the nanocrystalline character of the sample and a large number of IR peaks.

The Raman spectra of the $\mathrm{Gd}_{4} \mathrm{O}_{3} \mathrm{~F}_{6}$ oxyfluoride are shown in Fig. 6. Six peaks at about 127, 218, 340, 360, 415 and $460 \mathrm{~cm}^{-1}$ can be observed. The lower energy peaks are connected with the movement of heavy Gd-Gd pairs (127 and $\left.218 \mathrm{~cm}^{-1}\right) .{ }^{53}$ The vibrations of the Gd-O group are visible as a peak at $460 \mathrm{~cm}^{-1} .52$

Fig. 7 shows the XRD patterns of the nanosized $\mathrm{Gd}_{4} \mathrm{O}_{3} \mathrm{~F}_{6}$ : $\mathrm{Eu}^{3+}$ crystals. The positions of all peaks are in good agreement with those in the pattern calculated for monoclinic $\mathrm{Gd}_{4} \mathrm{O}_{3} \mathrm{~F}_{6}$ with the $P 2 / c$ space group. The single-phase product with the absence of any additional peaks from extraneous admixtures was obtained in the whole range of $\mathrm{Eu}^{3+}$ doping concentrations.

The structure of gadolinium offers two equivalent cationic sites $\mathrm{Gd}(\mathrm{I})$ and $\mathrm{Gd}(\mathrm{II})$ for possible substitution with $\mathrm{RE}^{3+}$ ions.

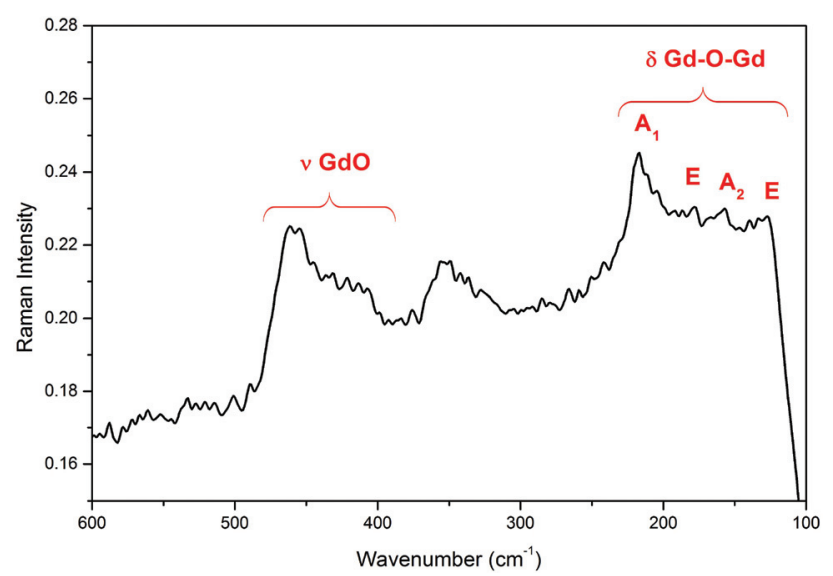

Fig. 6 Raman spectrum of $\mathrm{Gd}_{4} \mathrm{O}_{3} \mathrm{~F}_{6}$ nanocrystals.

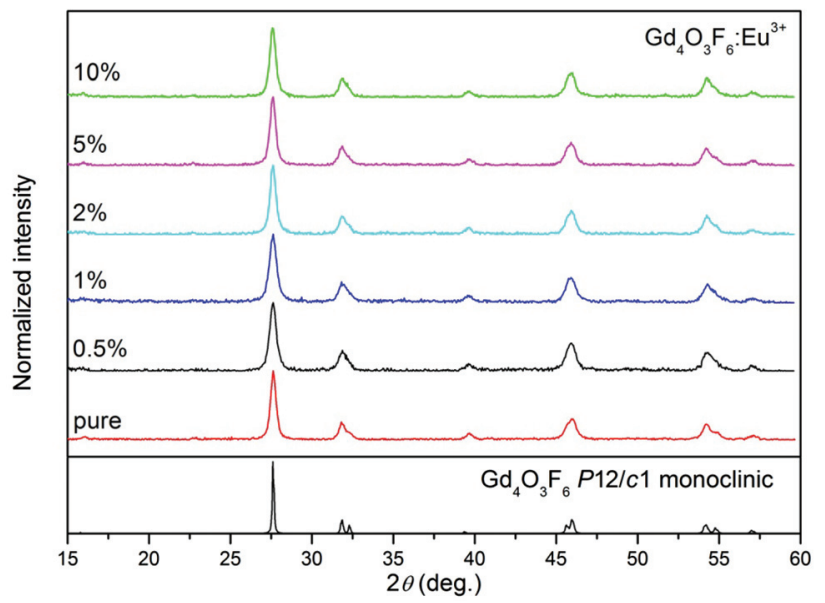

Fig. 7 XRD patterns of $\mathrm{Gd}_{4} \mathrm{O}_{3} \mathrm{~F}_{6}: \mathrm{Eu}^{3+}$ nanophosphors prepared by the sol-gel method and annealed at $500{ }^{\circ} \mathrm{C}$ for $2 \mathrm{~h}$. 
No preferential site substitution depending on the concentration of the dopant and annealing temperature has been observed. Besides, in comparison with the cell parameters for $0.5 \% \mathrm{~mol} \mathrm{Eu}{ }^{3+}$ ions doped $\mathrm{Gd}_{4} \mathrm{O}_{3} \mathrm{~F}_{6}(a=3.9421(7) \AA, \quad b=$ 11.2169(6) $\AA$, $c=5.5564(9) \AA$ and $\beta=134.97(4), V=173.81(731)$ ) the cell volume decreases insignificantly with the substitution of $\mathrm{Gd}^{3+}$ ions (ionic radius $1.107 \AA$ in ninefold coordination) with the dopants (the ionic radius of $\mathrm{Eu}^{3+}$ is $1.12 \AA$ ). ${ }^{54}$

\section{Luminescent properties}

Fig. 8-10 illustrate the luminescent properties of $\mathrm{Gd}_{4} \mathrm{O}_{3} \mathrm{~F}_{6}: \mathrm{Eu}^{3+}$ materials. Excitation spectra (Fig. 8a) in the range of 200-500 $\mathrm{nm}$ indicate the possibility of efficient excitation dopant emission in the $\mathrm{O}^{2-} \rightarrow \mathrm{Eu}^{3+}$ charge transfer band (CT) with maximum at $250 \mathrm{~nm}$. The presence of this band is a result of $\mathrm{O}^{2-}$ ions in the structure. ${ }^{55}$ The energy of $\mathrm{O}^{2-} \rightarrow \mathrm{Eu}^{3+}$ CT could be estimated using the following equation given by Jørgensen: ${ }^{56}$

$$
E_{\mathrm{CT}}=[\chi(\mathrm{L})-\chi(\mathrm{M})]\left(3 \times 10^{4}\right)
$$

where $E_{\mathrm{CT}}$ denotes the position of the CT band (in $\mathrm{cm}^{-1}$ ), $\chi(\mathrm{L})$ and $\chi(\mathrm{M})$ are the optical electronegativities of the anion and the central metal cation, respectively. For $\chi(\mathrm{O})=3.2$ and $\chi(\mathrm{Eu})$
$=1.75,^{57}$ the calculated CT position should be $43500 \mathrm{~cm}^{-1}$ (around $230 \mathrm{~nm}$ ). The measured positions of CT bands in the excitation spectra of obtained samples were at around $250 \mathrm{~nm}$. The red shift of the $\mathrm{CT}$ band resulted from the difference between bulk materials, for which eqn (2) was derived, and nano-sized phosphors. ${ }^{58-61}$

The remaining narrow excitation bands with maxima above $270 \mathrm{~nm}$ are related to the $\mathrm{f}-\mathrm{f}$ transitions of $\mathrm{Gd}^{3+}$ and $\mathrm{Eu}^{3+}$ ions. Their narrow character is a consequence of the shielding properties of the higher energetic $5 \mathrm{~d}$ and $6 \mathrm{~s}$ electron sublevels present in $\mathrm{Ln}^{3+}$ ions. These properties influence the impact of the surrounding local environment and therefore $\mathrm{f}-\mathrm{f}$ electronic transitions are relatively insensitive to the changes in ligands. These transitions are Laporte forbidden and due to that their intensities are low unlike that of the CT band, allowed by selection rules. The transition bands in the spectral range of 270-315 $\mathrm{nm}$ are connected with excitation of $\mathrm{Gd}^{3+}$ ions and confirm the energy transfer (ET) between $\mathrm{Gd}^{3+}$ and $\mathrm{Eu}^{3+}$ ions. ${ }^{40}$ The other peaks proved the direct excitation of $\mathrm{Eu}^{3+}$ ions. From the excitation spectra, $\mathrm{Eu}^{3+}$ ions at lower concentrations can be effectively excited not only in CT but also in ET bands. However, with increasing $\mathrm{Eu}^{3+}$ concentration, the ratio between CT and ET changes in favour of the former.
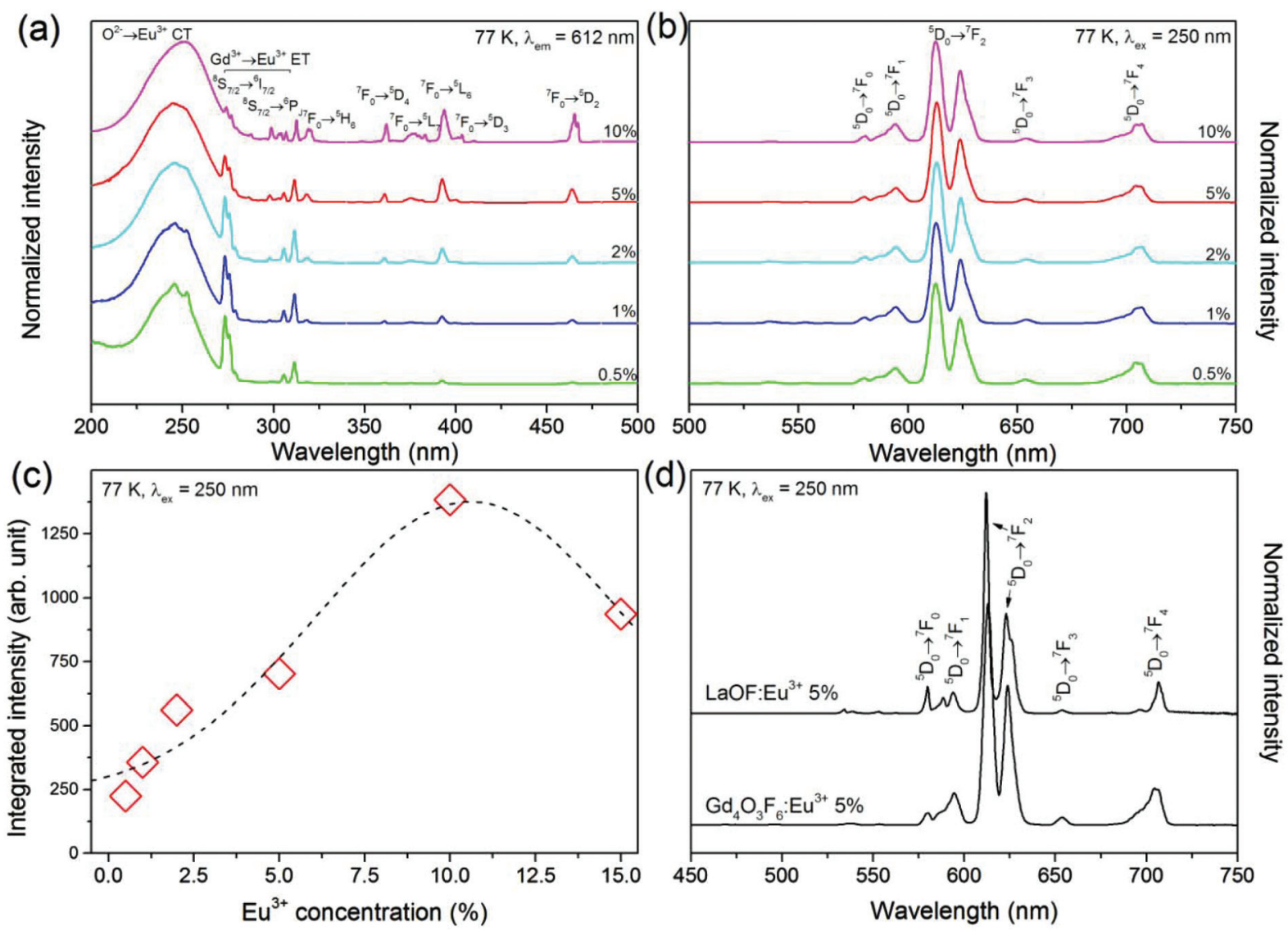

Fig. 8 Luminescence excitation (a) and emission (b) spectra of $\mathrm{Gd}_{4} \mathrm{O}_{3} \mathrm{~F}_{6}$ : $\mathrm{Eu}^{3+}$ samples; (c) integrated luminescence intensity as a function of Eu ${ }^{3+}$ ions concentration (dots represent integrated area under emission bands; the dotted line is nonlinear fit), (d) comparison of luminescence spectra of $\mathrm{LaOF}: \mathrm{Eu}^{3+}$ and $\mathrm{Gd}_{4} \mathrm{O}_{3} \mathrm{~F}_{6}: \mathrm{Eu}^{3+}$ samples measured under the same conditions. 


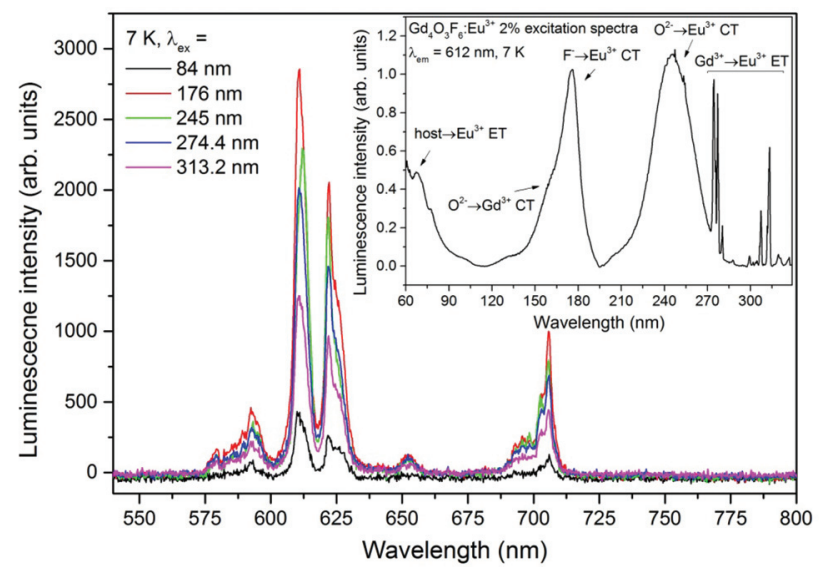

Fig. 9 Emission spectra of the $\mathrm{Gd}_{4} \mathrm{O}_{3} \mathrm{~F}_{6}: 2 \% \mathrm{Eu}^{3+}$ sample measured at $T=7 \mathrm{~K}$ with the use of different excitation wavelengths and the excitation spectrum of the $612 \mathrm{~nm}$ emission measured for the $\mathrm{Gd}_{4} \mathrm{O}_{3} \mathrm{~F}_{6}: 2 \%$ $\mathrm{Eu}^{3+}$ sample in the VUV and UV range.

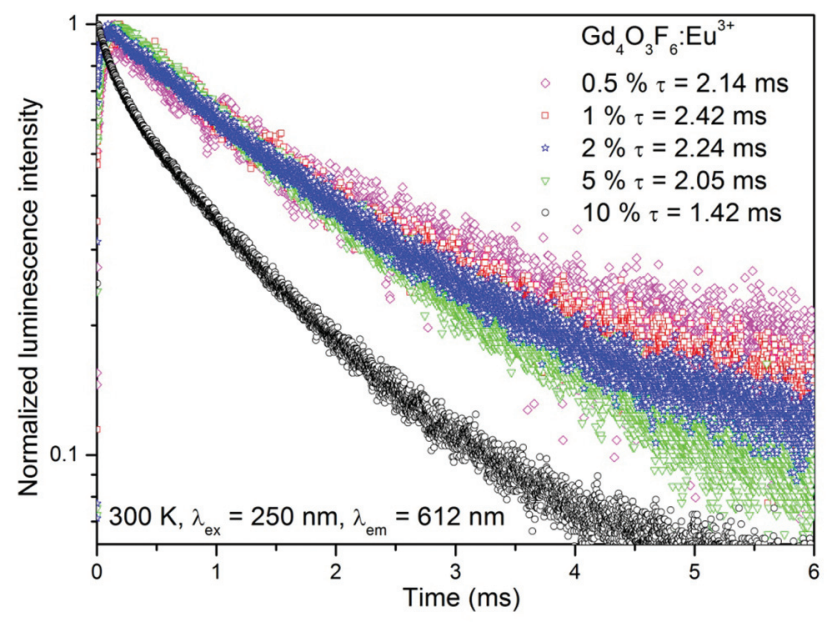

Fig. 10 Luminescence decays of $\mathrm{Gd}_{4} \mathrm{O}_{3} \mathrm{~F}_{6}: \mathrm{Eu}^{3+}$ samples.

The emission spectra obtained under excitation by $250 \mathrm{~nm}$ UV light are presented in Fig. 8b. All emission bands are due to the transitions from the ${ }^{5} \mathrm{D}_{0}$ excited level to the ${ }^{7} \mathrm{~F}_{J}$ components of the ground state. The most intense emission line observed at $612 \mathrm{~nm}$ is connected with one of the components of ${ }^{5} \mathrm{D}_{0} \rightarrow{ }^{7} \mathrm{~F}_{2}$ transition. The sensitivity of transitions within the f-electron shell of $\mathrm{RE}^{3+}$ ions to crystal field is relatively low. However, some of the $\mathrm{f}-\mathrm{f}$ transitions are prone to changes depending on the symmetry of the local environment. In the $\mathrm{Eu}^{3+}$ ion, the ${ }^{5} \mathrm{D}_{0} \rightarrow{ }^{7} \mathrm{~F}_{2}$ transition is sensitive to the $\mathrm{Eu}^{3+}$ local symmetry and becomes partially allowed when $\mathrm{Eu}^{3+}$ ions occupy sites of low symmetry (without an inversion symmetry). Its hypersensitivity is often used to track the structural changes in the $\mathrm{Eu}^{3+}$ host and surrounding coordination. ${ }^{62}$ In the $\mathrm{Gd}_{4} \mathrm{O}_{3} \mathrm{~F}_{6}$ host material, the $\mathrm{Eu}^{3+}$ ions are located in low symmetry sites, replacing $\mathrm{Gd} 1$ or $\mathrm{Gd} 2$ ions (both $C_{2 \mathrm{v}}$ ) that causes a relatively high intensity of the ${ }^{5} \mathrm{D}_{0} \rightarrow{ }^{7} \mathrm{~F}_{2}$ transition band.
The highest integral luminescence intensity was measured for the $10 \%$-doped sample. The value between 5 and $10 \%$ is typical of $\mathrm{Eu}^{3+}$ doped materials, whereas for higher doping the concentration quenching of the ${ }^{5} \mathrm{D}_{0}$ excited state occurs. ${ }^{49}$ This process can be attributed to the resonance energy transfer between neighbouring $\mathrm{Eu}^{3+}$ ions or by the transfer to the crystal defects and impurities. The energy resulting from the difference between ${ }^{5} \mathrm{D}_{0}$ and ${ }^{7} \mathrm{~F}_{J}$ manifolds can be cooperatively transferred between three or four nearest $\mathrm{Eu}^{3+}$ ions. ${ }^{63}$ The mechanism of interaction between $\mathrm{Eu}^{3+}$ ions depends on the critical distance between them. ${ }^{64}$ The energy transfer between $\mathrm{Eu}^{3+}$ ions may occur via one of the following mechanisms: exchange interaction, radiation reabsorption and multipolemultipole interactions. The critical distance between the donor and the acceptor can be calculated using the equation proposed by Blasse. ${ }^{65}$ In the $\mathrm{Gd}_{4} \mathrm{O}_{3} \mathrm{~F}_{6}$ host material, critical distance between $\mathrm{Eu}^{3+}$ ions was calculated to be $9.42 \AA$. For the distances greater than $5 \AA$, multipole-multipole interactions are dominant and are the major cause of concentration quenching.

The interactions between $\mathrm{Eu}^{3+}$ ions, observed in the oxyfluoride host previously, ${ }^{13}$ also affect the observed decays, which is discussed below. Phonon relaxation from the ${ }^{5} \mathrm{D}_{0}$ excited state to the ${ }^{7} \mathrm{~F}_{6}$ level is impossible in most cases due to a large energy gap between these states. This is particularly true for $\mathrm{Gd}_{4} \mathrm{O}_{3} \mathrm{~F}_{6}$ due the low phonon energy in this matrix, which is confirmed by Raman spectroscopy (see Fig. 6).

A comparison of the luminescence properties of tetragonal LaOF: $\mathrm{Eu}^{3+}$ and monoclinic $\mathrm{Gd}_{4} \mathrm{O}_{3} \mathrm{~F}_{6}: \mathrm{Eu}^{3+}$, prepared in the same way, shows their similarity but also important differences (see Fig. 8d). In the first instance, the shapes and widths of emission bands show that the number of different $\mathrm{Eu}^{3+}$ sites is higher in $\mathrm{Gd}_{4} \mathrm{O}_{3} \mathrm{~F}_{6}: \mathrm{Eu}^{3+}$. The ${ }^{5} \mathrm{D}_{0} \rightarrow{ }^{7} \mathrm{~F}_{0}$ transition band is forbidden by the selection rules of $\mathrm{f}-\mathrm{f}$ transitions, but it could be observed when $\mathrm{Eu}^{3+}$ ions occupy sites with $C_{\mathrm{s}}, C_{\mathrm{n}}$, or $C_{\mathrm{nv}}$ symmetry through the $J-J_{0}$ mixing effect which is really achieved in both structures. ${ }^{66}$ In the LaOF: $\mathrm{Eu}^{3+}$ material, the intensity of the ${ }^{5} \mathrm{D}_{0} \rightarrow{ }^{7} \mathrm{~F}_{0}$ line is higher which emphasizes the difference between these two materials. Also the shape of the ${ }^{5} \mathrm{D}_{0} \rightarrow{ }^{7} \mathrm{~F}_{0}$ line in the luminescence spectra of $\mathrm{Gd}_{4} \mathrm{O}_{3} \mathrm{~F}_{6}: \mathrm{Eu}^{3+}$ suggests that it is composed of at least two single peaks connected with two different sites of $\mathrm{Eu}^{3+}$ in the proposed crystal structure. The remaining emission lines in the luminescence spectrum of the $\mathrm{Gd}_{4} \mathrm{O}_{3} \mathrm{~F}_{6}: \mathrm{Eu}^{3+}$ material are broadened and more complex due to the stronger splitting of degenerate ${ }^{7} \mathrm{~F}_{J}$ states in $C_{2 \mathrm{v}}$ symmetry than in $C_{4 \mathrm{v}}$ in LaOF: $\mathrm{Eu}^{3+},{ }^{67}$ as the splitting is generally thinner in a site with lower symmetry.

Emission spectra of the $\mathrm{Gd}_{4} \mathrm{O}_{3} \mathrm{~F}_{6}: \mathrm{Eu}^{3+} 2 \%$ sample under excitation with different wavelengths selected from the UV-VUV range are presented in Fig. 9. The excitation spectrum measured for the $612 \mathrm{~nm}$ line in the UV-VUV range is presented in the inset as well. It clearly indicates that the emission of $\mathrm{Eu}^{3+}$ centres in the obtained material can be efficiently excited in the VUV range. The intensity of the $\mathrm{Eu}^{3+}$ emission is high under excitation in the fundamental absorption region below $100 \mathrm{~nm}$ (host-Eu ${ }^{3+}$ energy transfer), while wide and 
intense bands observed in the excitation spectra between 150 and $200 \mathrm{~nm}$ can be associated with $\mathrm{F}^{-} \rightarrow \mathrm{Eu}^{3+}$ and $\mathrm{O}^{2-} \rightarrow \mathrm{Gd}^{3+}$ $\mathrm{CT}$. The spectral range in which the $\mathrm{F}^{-} \rightarrow \mathrm{Eu}^{3+} \mathrm{CT}$ band can be observed can be determined from eqn (2). For $\chi(\mathrm{F})=3.9$ and $\chi(\mathrm{Eu})=1.75$, the calculated $\mathrm{CT}$ position should be at $64500 \mathrm{~cm}^{-1}$ (around $155 \mathrm{~nm}$ ). ${ }^{68}$ A similar position of the CT band (around $150 \mathrm{~nm}$ ) was experimentally obtained by Ptacek et al. in the spectra of $\mathrm{NaGdF}_{4}$ nanocrystals doped with $\mathrm{Eu}^{3+}$ ions. ${ }^{69}$ The calculated, in the same way, position of $\mathrm{O}^{2-} \rightarrow \mathrm{Gd}^{3+}$ CT should be around $145 \mathrm{~nm}$ (with the $\chi(\mathrm{Gd})=0.91$ ) and the $\mathrm{F}^{-} \rightarrow \mathrm{Gd}^{3+} \mathrm{CT}$ peak should be observed at around $89700 \mathrm{~cm}^{-1}$ $(111 \mathrm{~nm}) .^{70}$ The energy of CT between $\mathrm{O}^{2-}$ and $\mathrm{Gd}^{3+}$ ions can be different depending on the host material. It was observed that $\mathrm{O}^{2-} \rightarrow \mathrm{Gd}^{3+} \mathrm{CT}$ has higher energy when occurred in fluorides and the maximum of the $\mathrm{CT}$ band can be found at $123 \mathrm{~nm}$ and $131 \mathrm{~nm}$ in $\mathrm{YF}_{3}$ and $\mathrm{LaF}_{3}$ matrices, respectively. ${ }^{71}$ In materials containing $\mathrm{O}^{2-}$ ions, such as borates, aluminates and silicates, the maximum of the CT band can be found at lower energies than that predicted theoretically (155-184 nm). ${ }^{71,72}$ The energies of CT are generally dependent on the surrounding environment and can be different in various host materials. In our system, the $\mathrm{F}^{-} \rightarrow \mathrm{Eu}^{3+} \mathrm{CT}$ band is red-shifted with respect to the theoretical position. However, only the band with a maximum at $176 \mathrm{~nm}$ can be assigned to $\mathrm{F}^{-} \rightarrow \mathrm{Eu}^{3+} \mathrm{CT}$ because the expected intensity is higher than that of $\mathrm{O}^{2-} \rightarrow \mathrm{Gd}^{3+} \mathrm{CT}$. In the emission of $\mathrm{Eu}^{3+}$ ions excited by the $\mathrm{O}^{2-} \rightarrow \mathrm{Gd}^{3+} \mathrm{CT}$, the radiative relaxation of $\mathrm{Eu}^{3+}$ ions is preceded by the $\mathrm{Gd}^{3+} \rightarrow \mathrm{Eu}^{3+}$ energy transfer that decreases the efficiency of the whole process. The remaining excitation bands in the range from 200 to $330 \mathrm{~nm}$ are connected with $\mathrm{O}^{2-} \rightarrow \mathrm{Eu}^{3+} \mathrm{CT}$ and $\mathrm{Gd}^{3+} \rightarrow \mathrm{Eu}^{3+}$ energy transfer similarly to those shown in Fig. 8a and discussed above.

The highest intensity of the $\mathrm{Eu}^{3+}$ emission recorded upon excitation below $200 \mathrm{~nm}$ was recorded at $176 \mathrm{~nm}$. The properties of efficient excitation below $200 \mathrm{~nm}$ make this compound a suitable phosphor for vacuum ultraviolet applications, such as plasma display panels and Hg-free fluorescent lamps. ${ }^{33,73}$

Luminescence decay curves recorded for $\mathrm{Gd}_{4} \mathrm{O}_{3} \mathrm{~F}_{6}: \mathrm{Eu}^{3+}$ materials at room temperature are presented in Fig. 10. The decays are relatively fast for the $\mathrm{Eu}^{3+}$-doped materials; however, this is an advantage concerning their potential applications as red emitting phosphors. Average luminescence lifetimes were calculated by applying the following equation: ${ }^{74}$

$$
\tau=\frac{\int_{0}^{\infty} t I(t) \mathrm{d} t}{\int_{0}^{\infty} I(t) \mathrm{d} t} \approx \frac{\int_{0}^{\max } t I(t) \mathrm{d} t}{\int_{0}^{\max } I(t) \mathrm{d} t}
$$

where $I(t)$ represents the luminescence intensity at time $t$ corrected for the background and the integrals are evaluated in the range $0<t<t_{\max }$, where $t_{\max } \gg \tau$.

The longest luminescence lifetime was calculated for the 1\%-doped sample. Higher concentrations of $\mathrm{Eu}^{3+}$ ions caused a decrease in lifetime, which resulted from the above-mentioned concentration quenching. All depicted curves show a short rise in their intensities after the laser pulse, especially visible for the samples with low $\mathrm{Eu}^{3+}$ concentration. This phenomenon is caused by interactions between $\mathrm{Eu}^{3+}$ ions, fully described elsewhere. ${ }^{13}$ In short, $\mathrm{Eu}^{3+}$ ions can exchange their energies after excitation in several ways. Energy transfer from the ${ }^{5} \mathrm{D}_{J}(J>0)$ manifold to another $\mathrm{Eu}^{3+}$ ion in the ${ }^{7} \mathrm{~F}_{J}$ ground state can occur, which affects the relaxation dynamics, or one of the excited $\mathrm{Eu}^{3+}$ ions transfers its entire energy to another excited $\mathrm{Eu}^{3+}$ ion in its ${ }^{5} \mathrm{D}_{0}$ state, doubling its energy and therefore pumping the emitting, ${ }^{5} \mathrm{D}_{0}$ state after nonradiative relaxation from higher excited states.

The emission spectra and luminescence decay curves measured at $300 \mathrm{~K}$ were used for the calculation of the JuddOfelt spectroscopic parameters by the method described earlier. ${ }^{75-77}$ According to the Judd-Ofelt theory, intensity parameters contain contributions from the forced electric dipole and dynamic coupling mechanisms and provide information about the surrounding environment of $\mathrm{Eu}^{3+}$ ions. $^{76-79}$ The calculated $\Omega_{2}$ and $\Omega_{4}$ parameters are sensitive to the character of $\mathrm{Eu}^{3+}$ local environment. The changes in the $\Omega_{2}$ parameter bring information on the covalency of the $\mathrm{Eu}^{3+}$ ion environment. Its value is high for all samples studied, which confirms highly polarized surrounding of $\mathrm{Eu}^{3+}$ ions. This parameter is also connected with the average site symmetry and is high for the sites with low symmetry. The value of $\Omega_{2}$ slightly increases with the growing amount of $\mathrm{Eu}^{3+}$ ions in the matrix. This could be a result of distortions appearing at the $\mathrm{Eu}^{3+}$ site. The value of $\Omega_{4}$ parameter could be gained by lowering the covalence of the chemical bond between the $\mathrm{Eu}^{3+}$ ion and $\mathrm{O}^{2-}$ ligand ions. ${ }^{80}$ The electron density decreasing on ligands results in an increase in $\Omega_{4}$.

The calculated luminescence quantum efficiencies were high for the samples with $\mathrm{Eu}^{3+}$ concentration up to 5\%, which confirms the effectiveness of the prepared materials as phosphors and good properties of $\mathrm{Gd}_{4} \mathrm{O}_{3} \mathrm{~F}_{6}$ as a host material. The decreased efficiency in the $10 \%$-doped sample was a result of the earlier mentioned cross-relaxation between $\mathrm{Eu}^{3+}$ ions. According to Fig. 8c, the highest quantum efficiency should be expected for the $10 \%$-doped sample, for which the most intense luminescence was observed. However, the method used for the calculations, includes also nonradiative processes, being inversely proportional to the luminescence lifetimes. Hence, from the calculated total decay rates (see Table 2) we can estimate that the absorption of light is the highest for the $10 \%$-doped sample; however, there are some quenching pro-

Table 2 Judd-Ofelt parameters and luminescence quantum yields calculated for the obtained oxyfluorides: radiative, nonradiative and total deactivation rates $\left(A_{\text {rad }}, A_{\text {nrad }}\right.$ and $\left.A_{\text {tot }}\right)$, Judd-Ofelt intensity parameters $\left(\Omega_{2}\right.$ and $\left.\Omega_{4}\right)$ and quantum yields $(\eta)$

\begin{tabular}{llrllll}
\hline $\begin{array}{l}\text { Eu } \\
(\%)\end{array}$ & $\begin{array}{l}A_{\text {rad }} \\
\left(\mathrm{s}^{-1}\right)\end{array}$ & $\begin{array}{l}A_{\text {nrad }} \\
\left(\mathrm{s}^{-1}\right)\end{array}$ & $\begin{array}{l}A_{\text {tot }} \\
\left(\mathrm{s}^{-1}\right)\end{array}$ & $\begin{array}{l}\Omega_{2} \\
\left(10^{-20} \mathrm{~cm}^{2}\right)\end{array}$ & $\begin{array}{l}\Omega_{4} \\
\left(10^{-20} \mathrm{~cm}^{2}\right)\end{array}$ & $\begin{array}{l}\eta \\
(\%)\end{array}$ \\
\hline 0.5 & 553 & 56 & 609 & 43.7 & 17.8 & 91 \\
1 & 496 & 84 & 580 & 41.0 & 11.1 & 85 \\
2 & 524 & 77 & 600 & 42.8 & 13.5 & 87 \\
5 & 573 & 5 & 577 & 45.2 & 19.2 & 99 \\
10 & 582 & 222 & 804 & 48.2 & 14.8 & 72
\end{tabular}


cesses (like concentration quenching) which are reflected in high nonradiative rates and therefore low quantum efficiency.

\section{Conclusions}

Gadolinium oxyfluoride $\mathrm{Gd}_{4} \mathrm{O}_{3} \mathrm{~F}_{6}$ with a new monoclinic crystal structure was successfully prepared by a modified Pechini's method. The prepared materials crystallized as the monoclinic phase in the $P 12 / c 1$ (13) space group. In this crystal structure two types of clusters $\mathrm{GdO}_{0.5} \mathrm{~F} \cdot \mathrm{O}_{0.5}$ and $\mathrm{GdF}_{2} \cdot \mathrm{O}_{0.5}$ are located. Thermo-gravimetric analysis (TGA) was used to observe the transformation from an amorphous polymeric precursor to a crystalline powder, which provided information about optimal annealing conditions. X-ray diffraction (XRD) analysis, IR spectroscopy and Raman spectrum confirmed the monoclinic structure of the nanopowders obtained at $500{ }^{\circ} \mathrm{C}$. Crystal structure parameters were determined with the help of the Rietveld analysis and compared with the reference data. The transmission electron microscopy and EDX spectrum proved the formation of gadolinium oxyfluoride with the average grain size of $30 \mathrm{~nm}$.

The nanophosphors were effectively excited by the radiation from the vacuum ultraviolet range with the wavelength of $\lambda_{\text {ex }}=$ $176 \mathrm{~nm}$ and by the UV light, with the wavelength of $\lambda_{\text {ex }}=$ $250 \mathrm{~nm}$. For the efficient excitation by VUV light, the $\mathrm{F}^{-} \rightarrow \mathrm{Eu}^{3+}$ and $\mathrm{O}^{2-} \rightarrow \mathrm{Gd}^{3+} \mathrm{CT}$ processes are suggested to be responsible. The excitation band related to the $\mathrm{O}^{2-} \rightarrow \mathrm{Eu}^{3+} \mathrm{CT}$ allows the excitation in the UV range. The materials doped with $\mathrm{Eu}^{3+}$ ions showed intense red luminescence. The recorded emission spectra were used for calculation of the Judd-Ofelt intensity parameters indicating highly polarized local environment and low symmetry of sites occupied by $\mathrm{Eu}^{3+}$ ions. The most effective dopant concentration was estimated to be $10 \%$. Although the decay times of the emission of $\mathrm{Eu}^{3+}$ ions were relatively short, ranging from 1.42 to $2.42 \mathrm{~ms}$, the calculated luminescence quantum yields were high which makes the prepared materials interesting phosphors sensitive to the VUV and UV excitation.

\section{Acknowledgements}

Funding for this research was provided by the National Science Centre (grant no. DEC-2011/03/D/ST5/05701). T.G. holds a scholarship from the Foundation for Polish Science for Young Scientists (FNP).

This work was supported in part by the European Community Research Infrastructure Action under the FP6 Structuring the European Research Area Programme (through the Integrated Infrastructure Initiative Integrating Activity on Synchrotron and Free Electron Laser Science) and by the Estonian Research Council-Institutional Research Funding IUT02-26.

\section{Notes and references}

1 P. Berdowski, M. J. J. Lammers and G. Blasse, Chem. Phys. Lett., 1985, 113, 387-390.

2 J. Holsa, Acta Chem. Scand., 1991, 45, 583-587.

3 J. Hölsä and E. Kestilä, J. Alloys Compd., 1995, 225, 89-94.

4 J. Hölsä, E. Kestilä, P. Ylha, E. Antic-Fidancev, M. LemaitreBlaise, P. Porcher, P. Deren and W. Strek, J. Appl. Spectrosc., 1995, 62, 697-705.

5 S. Fujihara, T. Kato and T. Kimura, J. Mater. Sci. Lett., 2001, 20, 687-689.

6 J. Kyu Park, C.-H. Han, C. Hae Kim, H. D. Park and S. Y. Choi, J. Mater. Sci. Lett., 2003, 22, 477-478.

7 E. Antic-Fidancev, J. Hölsä, J.-C. Krupa and M. Lastusaari, J. Alloys Compd., 2004, 380, 303-309.

8 D. Gao, H. Zheng, X. Zhang, Z. Fu, Z. Zhang, Y. Tian and M. Cui, Appl. Phys. Lett., 2011, 98, 011907.

9 X. Zhang, D. Gao and L. Li, J. Appl. Phys., 2010, 107, 123528 .

10 E. He, H. Zheng, Z. Zhang, X. Zhang, L. Xu, Z. Fu and Y. Lei, J. Nanosci. Nanotechnol., 2010, 10, 1908-1912.

11 T. Passuello, F. Piccinelli, M. Pedroni, M. Bettinelli, F. Mangiarini, R. Naccache, F. Vetrone, J. A. Capobianco and A. Speghini, Opt. Mater., 2011, 33, 643-646.

12 T. Passuello, F. Piccinelli, M. Pedroni, S. Polizzi, F. Mangiarini, F. Vetrone, M. Bettinelli and A. Speghini, Opt. Mater., 2011, 33, 1500-1505.

13 T. Grzyb and S. Lis, Inorg. Chem., 2011, 50, 8112-8120.

14 M. Shang, G. Li, X. Kang, D. Yang, D. Geng, C. Peng, Z. Cheng, H. Lian and J. Lin, Dalton Trans., 2012, 41, 55715580 .

15 T. Grzyb, M. Węcławiak and S. Lis, J. Alloys Compd., 2012, 539, 82-89.

16 W. H. Zachariasen, Acta Crystallogr., 1951, 4, 231-236.

17 D. B. Shinn and H. A. Eick, Inorg. Chem., 1969, 8, 232-235.

18 A. Popov and G. Knudson, J. Am. Chem. Soc., 1954, 76, 3921-3922.

19 N. Baenziger, J. Holden, G. Knudson and A. Popov, J. Am. Chem. Soc., 1954, 76, 4734-4735.

20 J. Müller and T. Petzel, J. Alloys Compd., 1995, 224, 18-21.

21 J. W. Fergus, J. Mater. Sci. Lett., 1997, 16, 267-269.

22 A. W. Mann and D. J. M. Bevan, J. Solid State Chem., 1972, 5, 410-418.

23 J. Müller, Thermochim. Acta, 1997, 298, 109-114.

24 S. Schmid, Acta Crystallogr., Sect. B: Struct. Sci., 1998, 54, 391-398.

25 A. de Kozak, M. Samouël and A. Chretien, Rev. Chim. Miner., 1975, 10, 259.

26 M. Takashima, S. Yonezawa, K. Horita, K. Ohwaki and H. Takahashi, J. Mater. Chem., 1996, 6, 795.

27 M. Takashima, S. Yonezawa, J. H. Kim and S. Nishibu, J. Ind. Eng. Chem., 2004, 10, 1230-1241.

28 M. Takashima, S. Yonezawaa and M. Leblanc, Solid State Ionics, 2002, 154-155, 547-553.

29 M. Takashima, S. Yonezawa, T. Tanioka, Y. Nakajima and M. Leblanc, Solid State Sci., 2000, 2, 71-76. 
30 M. Takashima, S. Yonezawa and Y. Ukuma, J. Fluorine Chem., 1998, 87, 229-234.

31 M. Takashima and G. Kano, Solid State Ionics, 1987, 23, 99106.

32 J.-C. G. Bünzli and C. Piguet, Chem. Soc. Rev., 2005, 34, 1048-1077.

33 Q. Y. Zhang and X. Y. Huang, Prog. Mater. Sci., 2010, 55, 353-427.

34 K. Binnemans, Chem. Rev., 2009, 109, 4283-4374.

35 J.-C. G. Bünzli, Acc. Chem. Res., 2006, 39, 53-61.

36 T. Grzyb, M. Runowski, A. Szczeszak and S. Lis, J. Solid State Chem., 2013, 200, 76-83.

37 A. Szczeszak, T. Grzyb, B. Barszcz, V. Nagirnyi, A. Kotlov and S. Lis, Inorg. Chem., 2013, 52, 4934-4940.

38 S. Okamoto, R. Uchino, K. Kobayashi and H. Yamamoto, J. Appl. Phys., 2009, 106, 013522.

39 J. Krupa and M. Queffelec, J. Alloys Compd., 1997, 250, 287292.

40 R. T. Wegh, H. Donker, K. D. Oskam and A. Meijerink, Science, 1999, 283, 663-666.

41 J. Dexpert-Ghys, R. Mauricot, B. Caillier, P. Guillot, T. Beaudette, G. Jia, P. A. Tanner and B.-M. Cheng, J. Phys. Chem. C, 2010, 114, 6681-6689.

42 S. Dutta, S. Som and S. K. Sharma, Dalton Trans., 2013, 42, 9654.

43 A. K. Ambast, J. Goutam, S. Som and S. K. Sharma, Spectrochim. Acta, Part A, 2014, 122, 93-99.

44 C. C. Lin and R.-S. Liu, J. Phys. Chem. Lett., 2011, 2, 1268-1277. 45 M. Pechini, US Pat., US3330697A, 1967.

46 H. M. Rietveld, J. Appl. Crystallogr., 1969, 2, 65-71.

47 L. Lutterotti and M. Bortolotti, Compcomm. Newslett., 2003, 1, 43-50.

48 G. Zimmerer, Radiat. Meas., 2007, 42, 859-864.

49 M. Weber, Phys. Rev., 1968, 171, 283-291.

50 K. T. Jacob, V. S. Saji and Y. Waseda, Int. J. Appl. Ceram. Technol., 2006, 3, 312-321.

51 G. N. Kustova, K. F. Obzherina and L. R. Batsanova, J. Appl. Spectrosc., 1968, 9, 947-950.

52 J. Hölsä, E. Säilynoja, H. Rahiala and J. Valkonen, Polyhedron, 1997, 16, 3421-3427.

53 J. Hölsä, Spectrochim. Acta, Part A, 1993, 49, 465-470.

54 R. D. Shannon, Acta Crystallogr., Sect. A: Cryst. Phys., Diffr., Theor. Gen. Cryst., 1976, 32, 751-767.

55 P. Dorenbos, J. Phys.: Condens. Matter, 2003, 15, 8417-8434.
56 C. K. Jørgensen, Electron Transfer Spectra, John Wiley \& Sons, Inc., 1970.

57 C. Liu, J. Liu and K. Dou, J. Phys. Chem. B, 2006, 110, 20277-20281.

58 J. C. Boyer, F. Vetrone, J. A. Capobianco, A. Speghini and M. Bettinelli, J. Phys. Chem. B, 2004, 108, 20137-20143.

59 Z. Fu, S. Zhou, T. Pan and S. Zhang, J. Lumin., 2007, 124, 213-216.

60 G. Hodes, Adv. Mater., 2007, 19, 639-655.

61 L. Liu, E. Ma, R. Li, G. Liu and X. Chen, Nanotechnology, 2007, 18, 015403.

62 K. Binnemans and C. Görller-Walrand, J. Rare Earths, 1996, 14, 173-180.

63 D. B. Pi, F. Wang, X. P. Fan, M. Q. Wang and Y. Zhang, Spectrochim. Acta, Part A, 2005, 61, 2455-2459.

64 S. Som and S. K. Sharma, J. Phys. D: Appl. Phys., 2012, 45, 415102.

65 G. Blasse, Phys. Lett. A, 1968, 28, 444-445.

66 F. Fong, L. Vredevoe and R. De Wames, Phys. Rev., 1968, 170, 412-417.

67 S. Cotton, Lanthanide and Actinide Chemistry, 2nd edn, 2006.

68 G. Blasse, J. Phys. Chem. Solids, 1989, 50, 99.

69 P. Ptacek, H. Schäfer, O. Zerzouf, K. Kömpe and M. Haase, Cryst. Growth Des., 2010, 10, 2434-2438.

70 F. Zhang, Y. Wang and Y. Tao, Phys. Procedia, 2012, 29, 5561.

71 Y. H. Wang, T. Endo, X. Guo, Y. Murakami and M. Ushirozawa, J. Soc. Inf. Disp., 2004, 12, 495.

72 Y. Wang, X. Guo, T. Endo, Y. Murakami and M. Ushirozawa, J. Solid State Chem., 2004, 177, 2242-2248.

73 C. H. Kim, I. E. Kwon, C. H. Park, Y. J. Hwang, H. S. Bae, B. Y. Yu and C. H. Pyun, J. Alloys Compd., 2000, 311, 33-39.

74 J. R. Lakowicz, Principles of Fluorescence Spectroscopy, Springer, Baltimore, 3rd edn, 2006.

75 C. Kodaira, J. Lumin., 2003, 101, 11-21.

76 G. S. Ofelt, J. Chem. Phys., 1962, 37, 511.

77 B. Judd, Phys. Rev., 1962, 127, 750-761.

78 C. K. Jørgensen and R. Reisfeld, J. Less-Common Met., 1983, 93, 107-112.

79 B. M. Walsh, Adv. Spectrosc. Lasers Sens., 2006, 403-433.

80 S. Tanabe, T. Hanada, T. Ohyagi and N. Soga, Phys. Rev. B: Condens. Matter, 1993, 48, 10591-10594. 